Research Paper

\title{
Hypoxia mediated release of endothelial microparticles and increased association of S100A12 with circulating neutrophils
}

\author{
Rebecca V. Vince, ${ }^{1}$ Bryna Chrismas, ${ }^{1}$ Adrian W. Midgley, ${ }^{1}$ Lars R. McNaughton' and Leigh A. Madden ${ }^{2, *}$ \\ 'Department of Sport, Health and Exercise Science; and 2Postgraduate Medical Institute; University of Hull; Hull, United Kingdom
}

Key words: microparticles, VCAM-1, S100A12, hypoxia, oxidative stress, endothelium, RAGE

\begin{abstract}
Microparticles are released from the endothelium under normal homeostatic conditions and have been shown elevated in disease states, most notably those characterised by endothelial dysfunction. The endothelium is sensitive to oxidative stress/status and vascular cell adhesion molecule-1 (VCAM-1) expression is upregulated upon activated endothelium, furthermore the presence of VCAM-1 on microparticles is known. S100A12, a calcium binding protein part of the $S 100$ family, is shown to be present on circulating leukocytes and is thought a sensitive marker to local inflammatory process, which may be driven by oxidative stress. Eight healthy males were subjected to breathing hypoxic air $\left(15 \% \mathrm{O}_{2}\right.$, approximately equivalent to 3000 metres altitude) for 80 minutes in a temperature controlled laboratory and venous blood samples were processed immediately for VCAM-1 microparticles (VCAM-1 MP) and S100A12 association with leukocytes by flow cytometry. A pre-hypoxic blood sample was used for comparison. Both VCAM-1 MP and S100A12 association with neutrophils were significantly elevated post hypoxic breathing later declining to levels observed in the pre-test samples. A similar trend was observed in both cases and a correlation may exist between these two markers in response to hypoxia. These data offer evidence using novel markers of endothelial and circulating blood responses to hypoxia.
\end{abstract}

\section{Introduction}

During periods of hypoxia, cells are metabolically compromised resulting in cellular dysfunction that can eventually lead to cell death through metabolic failure. Neutrophils bound to the endothelial surface accelerate endothelial cell dysfunction and tissue destruction through a variety of cytotoxic mechanisms. In addition to physically plugging capillaries, ${ }^{1}$ activated neutrophils mediate a variety of harmful responses, such as production of reactive oxygen species (ROS), cytotoxic enzymes and cytokines. ${ }^{2}$ Many of these also recruit additional neutrophils and enhance their adhesiveness to the vascular endothelium. The attachment of neutrophils

*Correspondence to: Leigh A. Madden; Postgraduate Medical Institute; Room 003; Hardy Building; University of Hull; Hull HU6 7RX United Kingdom; Tel./Fax: +44.1482.466031; Email: I.a.madden@hull.ac.uk

Submitted: 11/28/08; Revised: 12/10/2008; Accepted: 12/11/08

Previously published online as an Oxidative Medicine and Cellular Longevity E-publication: http://www.landesbioscience.com/journals/oximed/article/761 1 to the vascular endothelium is mediated by adhesion glycoprotein complexes expressed both on the surface of the neutrophil and on the surface of the endothelial cell. ROS, in large quantities, disrupt the redox balance of cells resulting in oxidative stress and damage to membrane structures (possibly leading to membrane microparticle release), protein damage and cause the activation of signal transduction pathways that lead to apoptosis. ${ }^{3}$

Microparticles (MP) are cell membrane fragments released into the circulation to a certain extent in healthy individuals under normal homeostatic conditions ${ }^{4}$ and release is increased under stress conditions and disease. MP are released through either cellular activation or apoptosis. ${ }^{5}$ We recently observed a correlation between vascular cell adhesion molecule-1 (VCAM-1) positive MP $\left(\mathrm{VCAM}^{+} \mathrm{MP}\right)$ released from the endothelium and oxidant status, ${ }^{6}$ as measured by thiobarbituric acid reactive substances (TBARS), which is a measure of lipid peroxidation. Previous to this observation, a circadian rhythm in $\mathrm{VCAM}^{+} \mathrm{MP}$ was observed in healthy males, that along with additional data acquired within this group allowed a normal homoeostatic range to be established. ${ }^{7}$

VCAM-1 is an adhesion molecule, expressed on activated endothelium, being involved in leukocyte attachment and transmigration and is a therapeutic target in inflammatory disease. ${ }^{8}$ Endothelial MP offer an insight into the state of the endothelium as they carry surface antigens particular to the cell of origin and furthermore these MP can be routinely analysed with specific antibodies by flow cytometry. ${ }^{5,9}$ The endothelium is sensitive to oxidative stress ${ }^{10}$ and produces nitric oxide $(\mathrm{NO})$ via induction of inducible nitric oxide synthase (iNOS) and constitutively expressed endothelial nitric oxide synthase (eNOS). The endothelium may become activated in times of oxidative stress and this can result in cellular remodelling and the release of MP. ${ }^{11}$ Diseases, particularly those characterised by endothelial dysfunction, have been shown to result in an elevated concentration of endothelial derived MP. ${ }^{5}$

S100A12, a calcium binding protein belonging to the $S 100$ family, acts as a ligand for the multiligand cell surface receptor for advanced glycation end products (RAGE) ${ }^{12}$ and soluble RAGE (sRAGE). S100 proteins have been implicated in intracellular and extracellular regulatory processes and been shown to mediate inflammatory responses. ${ }^{13}$ S100A12 is secreted by activated neutrophils and inflamed tissue. ${ }^{14}$ S100A12 has been shown to interact with RAGE present on the endothelium to trigger an activated state (through NFKB pathway) resulting in induction of VCAM-1 and 
enhanced expression of intercellular adhesion molecule-1 (ICAM-1) in HUVECS that can aid in further recruitment of leukocytes to the injured endothelial cells. ${ }^{12}$

The aim of this study was to quantify the effects of oxidative stress, induced by breathing air equivalent to approximately 3,000 metres $(\mathrm{m})$ altitude $(15 \% \text { oxygen })^{15}$ on circulating $\mathrm{VCAM}^{+} \mathrm{MP}$ concentration, thus gaining an insight into the endothelial response to hypoxia and furthermore to correlate this response with a novel stress marker, S100A12, associated with the circulating blood cell population of neutrophils and monocytes.

\section{Results}

Venous blood samples were taken on numerous days, prior to the hypoxic breathing, to establish a normal range of values in healthy male subjects over a 24 hour $(\mathrm{h})$ period. This data was added to our previously published data that demonstrated a circadian rhythm and resulted in an overall mean of 1350 $\mathrm{VCAM}^{+} \mathrm{MP}$ per microlitre $(\mu \mathrm{L})$ of platelet poor plasma (PPP), with a mean coefficient of variation of $44 \%$ ( $n=$ 190). $\mathrm{VCAM}^{+} \mathrm{MP}$ levels are higher in the morning hours, reaching a minima late afternoon and again in the night. For this reason, the hypoxic (15\% Oxygen) treatment was scheduled for 09:00, after which a decrease in $\mathrm{VCAM}^{+} \mathrm{MP}$ is normally observed. There was a significant effect for time $(\mathrm{F}=11.9 ; \mathrm{p}<0.001)$ for $\mathrm{VCAM}^{+} \mathrm{MP}$ (Fig. $1)$, where post-hypoxic breathing (11:00), there was a large increase from $1020 \pm 263$ to $3600 \pm 1040$ per $\mu \mathrm{L} \mathrm{PPP}(\mathrm{p}=0.001)$, a value well outside the established normal range. Thereafter, $\mathrm{VCAM}^{+} \mathrm{MP}$ decreased towards the normal range, but at 14:00 was still significantly higher than at 08:00 $(\mathrm{p}=0.010)$. After this time no significant changes were observed in relation to the pre-test value.

There was a significant effect for time $(F=7.3$; $p<0.001)$ for TBARS (Fig. 1), where TBARS demonstrated a small non-significant increase from 08:00 to 14:00, and thereafter, a marked downward trend. TBARS at 20:00 was significantly lower than at 11:00 $(\mathrm{p}=0.013)$ and 14:00 $(\mathrm{p}=0.029)$ and significantly lower at 17:00 than $14: 00(\mathrm{p}=0.047)$.

S100A12 association with monocytes (S100A12 $\left.{ }_{\text {mono }}\right)$ and neutrophils (S100A12 ${ }_{\text {neutro }}$ ) was assessed by flow cytometry. Typical forward scatter/side scatter and fluorescent antibody labelling of neutrophils and monocytes is shown in Figure 2. There was a significant effect for time for S100A12 ${ }_{\text {neutro }}(\mathrm{F}=9.1$; $\mathrm{p}<0.001)$ (Fig. 3), where a marked increase was observed immediately after hypoxic breathing $(\mathrm{p}<0.001)$. The S100A12 neutro remained elevated at 14:00 $(\mathrm{p}=0.044)$. The effect of time on $\mathrm{S} 100 \mathrm{~A} 12_{\text {mono }}$ (Fig. 3) was not statistically significant $(\mathrm{F}=1.3 ; \mathrm{p}=0.29)$.

Figure 2. Typical flow cytometry profiles showing (top) forward scatter/ side scatter with Netrophils and monocytes gated accordingly and (bottom) fluorescence profiles showing gated (black) neutrophils and (grey) monocytes incubated with either (filled) goat serum or (line) anti-human EN-RAGE.
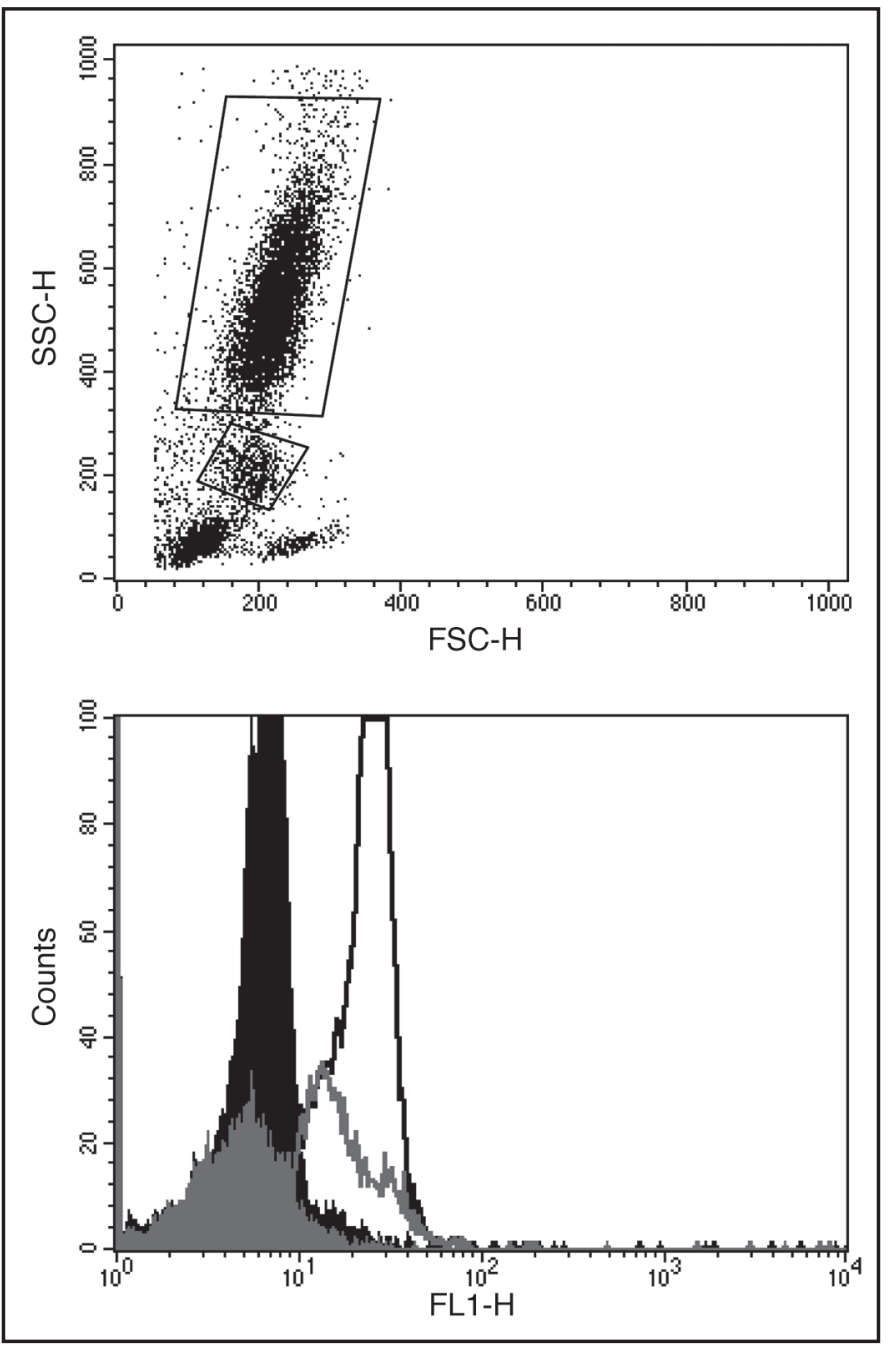


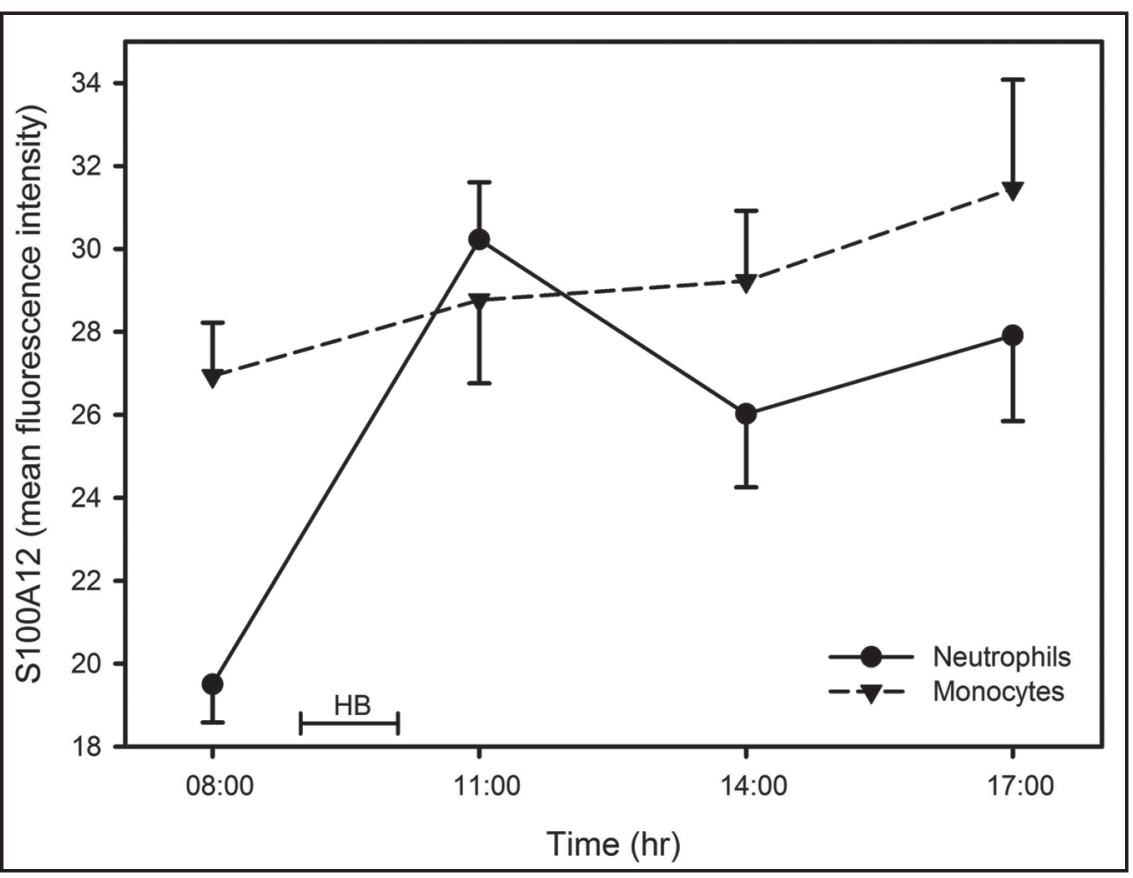

Figure 3. Time dependent profile for S100A12 expression on monocytes and neutrophils before and after hypoxic breathing. The data are represented as the mean and standard error of the mean $(n=8) . H B=$ time during which subjects breathed hypoxic air.

Significant relationships were observed between $\mathrm{VCAM}^{+} \mathrm{MP}$ and S100A12 ${ }_{\text {neutro }}\left(r_{s}=0.39 ; \mathrm{p}=0.044\right)$ and between $S 100 \mathrm{~A} 12_{\text {mono }}$ and $\mathrm{S} 100 \mathrm{~A} 12_{\text {neutro }}\left(\mathrm{r}_{\mathrm{s}}=0.74 ; \mathrm{p}<0.001\right)$.

\section{Discussion}

Endothelial MP have been proposed as a sensitive blood borne marker of endothelial state. ${ }^{4}$ The endothelium is known to be affected by oxidative stress and the subjects in this study were exposed to a significant oxidative stress by hypoxic breathing and subsequent re-oxygenation. This resulted in an increase in plasma TBARS, a measure of lipid peroxidation, and a marker of oxidative stress. Hypoxia leads to numerous cellular responses including generation of ROS and production of hypoxia-inducible factor- $1 .{ }^{16}$ Hypoxic breathing led to a significant increase in circulating $\mathrm{VCAM}^{+}$ MP (Fig. 1), demonstrating a novel measure of endothelial response to hypoxia. Whether or not these MP came from localised activated endothelium or hypoxia mediated endothelial activation is debatable. Previously we have reported a circadian variation in $\mathrm{VCAM}^{+}$ $\mathrm{MP}^{7}$ with an early morning peak decreasing into the afternoon. Conversely, the data presented here shows a large increase from early morning, after hypoxic breathing to levels well outside the normal range.

The synthesis of S100A12 by neutrophil granulocytes has been shown. ${ }^{17}$ The role of S100A12 has been implicated in the innate immune system in response to infection. The exact nature of S100A12 ligand interaction is unclear, it has been shown able to bind both itself and a range of other molecules and was suggested to act as a molecular chaperone in the presence of calcium. ${ }^{18}$ RAGE been identified as a receptor for S100A12. ${ }^{12}$ This RAGE interaction leads to initiation of pro-inflammatory signalling cascades via MAP-Kinase and NFKB, resulting in increased adhesion molecule expression. ${ }^{19}$ Increased serum concentrations of S100A12 have been shown in patients with severe bacterial infections. ${ }^{20}$ Furthermore, serum S100A12 maybe of use as a diagnostic marker in inflammatory bowel disease, ${ }^{21}$ arthritis ${ }^{22}$ and asthma. ${ }^{23}$ In inflammatory disease high concentrations of S100A12 have also been shown at local sites of inflammation such as synovial fluid, ${ }^{24}$ inflamed bowel mucosa ${ }^{25}$ and atherosclerotic lesions. ${ }^{26}$

S100A12 interaction with RAGE is capable of activation of endothelial, lymphocyte and macrophage cells directly. ${ }^{13}$ S100A12 has been postulated to be a novel marker of localised inflammatory processes in part due to its overexpression at local inflammatory sites. ${ }^{19}$ As S100A12 is a ligand for RAGE it may be postulated that there is either an increase in RAGE expression upon the neutrophil surface following hypoxia or a higher degree of circulating S100A12 is bound to the receptor. RAGE expression has previously been shown to be affected by hypoxia via hypoxiainducible factor- $1 .{ }^{27}$ Interaction between RAGE and its ligands has also been demonstrated to upregulate VCAM-1 expression on endothelium and promote other proinflammatory pathways. ${ }^{28}$ Furthermore endothelial cells release RAGE specific ligands in response to hypoxia, ${ }^{29}$ which could account for the observed increase of neutrophil associated S100A12.

The amount of S100A12 associated with both neutrophils and monocytes appear correlated in this study, suggesting a similar response to hypoxia, although the increase in the S100A12 subject mean was not found significant. The increase in S100A12 neutro following hypoxic breathing suggests S100A12 may also be a marker of oxidative stress in the circulating blood cell population. A significant correlation was observed between both endothelium and neutrophil reaction to hypoxia via release of $\mathrm{VCAM}^{+} \mathrm{MP}$ and S100A12 $2_{\text {neutro }}(\mathrm{p}=0.044)$. This may be expected as both cell types have intrinsic roles in hypoxia (especially $\mathrm{I} / \mathrm{R}$ injury) and localised inflammation, where VCAM-1 mediates firm attachment of neutrophils to the endothelium. A recent study found significant correlations between serum concentrations of advanced glycation products (AGE) and VCAM-1 and the soluble form of S100A12 in diabetic patients. ${ }^{30}$ It has already been suggested that serum levels of cell surface markers may in fact be MP associated and not entirely freely soluble, ${ }^{5}$ furthermore elevated endothelial MP concentration is established in diabetes. ${ }^{31}$ Therefore these data ${ }^{30}$ may well include $\mathrm{VCAM}^{+} \mathrm{MP}$ released from dysfunctional endothelium in diabetic patients and their correlation with S100A12, as observed in the present study. In addition advanced oxidation protein products have recently been shown to induce overexpression of VCAM-1 on endothelial cells via S100A12 mediated signalling. ${ }^{32,33}$ Induction of ROS generation and VCAM-1 expression was effectively prevented by blocking S100A12 binding to the endothelial surface. ${ }^{32}$

The effects of hypoxia on the vasculature are well characterised and here we highlight two potentially novel markers which link the blood response and endothelial response within healthy human subjects. Further research is necessary to elucidate the specific cellular mechanism and consequences behind these observations. 


\section{Table 1 Sequence of experimental events}

$\begin{array}{lc}\text { Time (h) } & \text { Experimental event } \\ \text { 07:15 } & \text { Subjects report to laboratory } \\ \text { 08:00 } & \text { Pre-hypoxia blood sample } \\ \text { 09:00 } & \text { Hypoxic breathing initiated } \\ 10: 20 & \text { Hypoxic breathing ended } \\ 11: 00 & 1^{\text {st }} \text { post-exposure blood sample } \\ 14: 00 & 2^{\text {nd }} \text { post-exposure blood sample } \\ 17: 00 & 3^{\text {rd }} \text { post-exposure blood sample } \\ 20: 00 & 4^{\text {th }} \text { post-exposure blood sample }\end{array}$

\section{Materials and Methods}

Eight healthy male volunteers (18-24 years old) participated in this study. All subjects gave written informed consent and ethical approval was granted by the Departmental ethics committee at the University of Hull. Subjects reported to a temperature-controlled laboratory at $07: 15$ on the day of the study and a pre-test blood sample was drawn at 08:00. Venous blood was obtained by venipuncture into potassium EDTA tubes (Vacuette ${ }^{\circledR}$, Greiner, UK) for analysis of both S100A12 and TBARS or sodium citrate tubes (Vacuette ${ }^{\circledR}$, Greiner, UK) for MP analysis pre- and post-exposure according to Table 1. Exposure consisted of breathing hypoxic air (15\% Oxygen, air mix) produced by a hypoxicator for 80 minutes (min), through masks. The hypoxic exposure started at 09:00 and lasted $80 \mathrm{~min} ; 15 \%$ Oxygen is equivalent to approximately $3000 \mathrm{~m}$ altitude. $^{15}$

MP quantification. Citrated blood was analysed according the method of Hugel et al. ${ }^{34}$ Platelet rich plasma was obtained by centrifugation $(180 \mathrm{xg}, 10 \mathrm{~min})$ and this was further centrifuged $(13,000 \mathrm{xg}, 2 \mathrm{~min})$ to remove platelets. The now platelet poor plasma $25 \mu \mathrm{L}$ was then incubated with either Isotype matched $\operatorname{IgG}$ negative control FITC conjugate $(4 \mu \mathrm{L}, \mathrm{AbD}$ Serotec, UK) or IgG VCAM-1 specific FITC conjugate $(4 \mu \mathrm{L}$, AbD Serotec, UK) for 30 min. Quantification was achieved by adding counting beads $(25 \mu \mathrm{L}$, Caltag medsystems, UK) and $0.2 \mu \mathrm{m}$ filtered PBS $(200 \mu \mathrm{L})$ prior to flow cytometry.

S100A12 analysis. EDTA blood $(100 \mu \mathrm{L})$ was mixed with Erythrolyse (2 mL, AbD Serotec, UK) to selectively lyse red blood cells. The white cells were then pelleted by centrifugation ( $400 \mathrm{xg}, 5$ $\mathrm{min})$, washed and resuspened in PBS. Cells $\left(2 \times 10^{5}\right)$ were incubated with either goat serum, to control for non-specific binding, or goat anti-human EN-RAGE antibody (RnD Systems, UK). Cells were incubated with antibody for one hour before washing with PBS, centrifugation (400 $\mathrm{xg}, 5 \mathrm{~min})$ and incubating $(30 \mathrm{~min})$ with a secondary, FITC conjugated anti-goat IgG antibody (AbD Serotec, UK). Cells were washed as above and resuspended in a final volume of $300 \mu \mathrm{L}$ PBS prior to flow cytometry analysis.

Flow cytometry. For data acquisition a BD FACSCalibur (BD Biosciences, UK) was used and analysed using CellQuest software. For S100A12, 10,000 cells were counted and 50,000 events were counted for MP analysis. For S100A12 analysis leukocytes were gated according to forward scatter/side scatter characteristics and data is presented as mean fluorescence intensity (MFI) on the FL-1 scale of the cells incubated with anti-human EN-RAGE minus the MFI obtained with goat serum.
TBARS analysis. EDTA plasma was obtained via centrifugation of the EDTA Vacuette ${ }^{\circledR}(10 \mathrm{~min}, 1500 \mathrm{xg})$ and stored at $-80^{\circ}$ Centigrade until analysed. Plasma TBARS was then analysed using a commercially available kit (Zeptometrix) following manufacturers' instructions and are expressed as malondialdeyde equivalents.

Statistical analysis. All statistical analyses were completed using SPSS for Windows version 16.0 (SPSS Inc., Chicago, IL). Normality for each dependent variable for each time point was checked using Q-Q plots and deemed plausible in each instance. Sample descriptive statistics are reported as means and standard deviations. The effect of time on TBARS expression and S100A12 expression on both monocytes $\left(\right.$ S100A $\left.12_{\text {mono }}\right)$ and neutrophils $\left(\right.$ S100A12 $\left.2_{\text {neutro }}\right)$ was analyzed using one-way analysis of variance for repeated measures. The Huynh-Feldt corrected $\mathrm{p}$ value was reported where the sphericity assumption was violated (as identified by a significant Mauchly's test statistic). The $\mathrm{VCAM}^{+} \mathrm{MP}$ data showed considerably less variance at 08:00 in comparison with later time points. The $\mathrm{VCAM}^{+} \mathrm{MP}$ data was therefore analyzed using a linear mixed model incorporating an autoregressive repeated covariance structure. Sidak post hoc pairwise comparisons were used in the event of significant main effects. The relationship between $\mathrm{VCAM}^{+} \mathrm{MP}$ and S100A12 ${ }_{\text {neutro }}$ and between S100A12 mono and S100A12 ${ }_{\text {neutro }}$ were analyzed using the Spearman correlation. Two-tailed statistical significance was as accepted as $\mathrm{p}<0.05$.

\section{Acknowledgements}

The authors with to express their gratitude to Dr. Ric Lovell and Mr. Lee Taylor for blood collection and logistical support.

\section{References}

1. Schmid-Schonbein GW, Engler RL. Granulocytes as active participants in acute myocardial ischemia and infarction. Am J Cardiovasc Pathol 1987; 1:15-30.

2. Inauen W, Granger DN, Meininger CJ, Schelling ME, Granger HJ, Kvietys PR. Anoxiareoxygenation-induced, neutrophil-mediated endothelial cell injury: Role of elastase. Am J Physiol 1990; 259:925-31.

3. Semenza GL. Cellular and molecular dissection of reperfusion injury: ROS within and without. Circ Res 2000; 86:117-8.

4. Freyssinet JM. Cellular microparticles: What are they bad or good for? J Thromb Haem 2003; 1:1655-62.

5. Horstman LL, Jy W, Jimenez JJ, Ahn YS. Endothelial microparticles as markers of endothelial dysfunction. Front Biosci 2004; 9:1118-35.

6. Vince RV, McNaughton LR, Taylor L, Midgley AW, Laden G, Madden LA. Release of VCAM-1 associated endothelial microparticles following simulated SCUBA dives. Eur J Appl Physiol 2008; 105:507-13.

7. Madden LA, Vince RV, Sandstrom M, Taylor L, McNaughton L, Laden G. Microparticle associated vascular adhesion molecule-1 and tissue factor follow a circadian rhythm in healthy human subjects. Thromb Haem 2008; 99:909-15.

8. Yusuf-Makagiansar H, Anderson ME, Yakovleva TV, Murray JS, Siahaan TJ. Inhibition of LFA-1/ICAM-1 and VLA-4/VCAM-1 as a therapeutic approach to inflammation and autoimmune diseases. Medicinal Res Rev 2002; 22:146-67.

9. Morel O, Toti F, Hugel B, Freyssinet JM. Cellular microparticles: A disseminated storage pool of bioactive vascular effectors. Curr Opin Hematol 2004; 11:156-64.

10. Ungvari Z, Wolin MS, Csiszar A. Mechanosensitive production of reactive oxygen species in endothelial and smooth muscle cells: Role in microvascular remodeling? Antiox Redox Signal 2006; 8:1121-9.

11. Morel O, Toti F, Hugel B, Bakouboula B, Camoin-Jau L, Dignat-George F, Freyssinet JM. Procoagulant microparticles-Disrupting the vascular homeostasis equation? Arterio Thromb Vasc Biol 2006; 26:2594-604.

12. Hofmann MA, Drury S, Fu CF, Qu W, Taguchi A, Lu Y, et al. RAGE mediates a novel proinflammatory axis: A central cell surface receptor for S100/calgranulin polypeptides. Cell 1999; 97:889-901.

13. Roth J, Vogl T, Sorg C, Sunderkotter C. Phagocyte-specific S100 proteins: A novel group of proinflammatory molecules. Trends Immunol 2003; 24:155-8.

14. Boussac M, Garin J. Calcium-dependent secretion in human neutrophils: A proteomic approach. Electrophoresis 2000; 21:665-72.

15. Peacock AJ. ABC of oxygen: Oxygen at high altitude. Br Med J 1998; 317:1063-6.

16. Shohet RV, Garcia JA. Keeping the engine primed: HIF factors as key regulators of cardiac metabolism and angiogenesis during ischemia. J Molec Med 2007; 85:1309-15. 
17. Dellangelica EC, Schleicher CH, Santome JA. Primary structure and binding-properties of calgranulin-c, a novel s100-like calcium-binding protein from pig granulocytes. J Biol Chem 1994; 269:28929-36.

18. Hatakeyama T, Okada M, Shimamoto S, Kubota Y, Kobayashi R. Identification of intracellular target proteins of the calcium-signaling protein S100A12. Eur J Biochem 2004; 271:3765-75.

19. Yang Z, Tao T, Raftery MJ, Youssef P, Di Girolamo N, Geczy CL. Proinflammatory properties of the human S100 protein S100A12. J Leukoc Biol 2001; 69:986-94.

20. Kim MH, Choi YW, Choi HY, Myung KB, Cho SN. The expression of RAGE and EN-RAGE in leprosy. Br J Dermatol 2006; 154:594-601.

21. Foell D, Kucharzik T, Kraft M, Vogl T, Sorg C, Domschke W, Roth J. Neutrophil derived human S100A12 (EN-RAGE) is strongly expressed during chronic active inflammatory bowel disease. Gut 2003; 52:847-53.

22. Foell D, Roth J. Proinflammatory $\$ 100$ proteins in arthritis and autoimmune disease. Arthr Rheumat 2004; 50:3762-71.

23. Yang Z, Yan WX, Tedla N, Armishaw C, Di Girolamo N, Wang HW, et al. S100A12 provokes mast cell activation: A potential amplification pathway in asthma and innate immunity. J Allergy and Clinical Immunology 2007; 119:106-14.

24. Foell D, Kane D, Bresnihan B, Vogl T, Nacken W, Sorg C, et al. Expression of the pro-inflammatory protein S100A12 (EN-RAGE) in rheumatoid and psoriatic arthritis. Rheumatology 2003; 42:1383-9.

25. Leach ST, Yang Z, Messina I, Song CJ, Geczy CL, Cunningham AM, et al. Serum and mucosal S100 proteins, calprotectin (S100A8/S100A9) and S100A12, are elevated at diagnosis in children with inflammatory bowel disease. Scand J Gastroenterol 2007; 42:1321-31.

26. Burke AP, Kolodgie FD, Zieske A, Fowler DR, Weber DK, Varghese PJ, et al. Morphologic findings of coronary atherosclerotic plaques in diabetics-A postmortem study. Arterioscler Thromb Vasc Biol 2004; 24:1266-71.

27. Pichiule P, Schmidt AM, Vannucci S. Hypoxia inducible factor-1 mediates the expression of the receptor for advanced glycation endproducts following cerebral hypoxia/ischemia. Stroke 2007; 38:560.

28. Basta G. Receptor for advanced glycation endproducts and atherosclerosis: From basic mechanisms to clinical implications. Atherosclerosis 2008; 196:9-21.

29. Chang JS, Wendt T, Qu W, Kong LH, Zou YS, Schmidt AM, et al. Oxygen deprivation triggers upregulation of early growth response- 1 by the receptor for advanced glycation end products. Circ Res 2008; 102:905-13

30. Nakamura K, Yamagishi SI, Adachi H, Matsui T, Kurita-Nakamura Y, Takeuchi M, et al. Serum levels of soluble form of receptor for advanced glycation end products (sRAGE) are positively associated with circulating AGEs and soluble form of VCAM-1 in patients with type 2 diabetes. Microvasc Res 2008; 76:52-6.

31. Sabatier F, Darmon P, Hugel B, Combes V, Sanmarco M, Velut JG, et al. Type 1 and type 2 diabetic patients display different patterns of cellular microparticles. Diabetes 2002; 51:2840-5.

32. Basta G, Lazzerini G, Del Turco S, Ratto GM, Schmidt AM, De Caterina R. At least 2 distinct pathways generating reactive oxygen species mediate vascular cell adhesion molecule-1 induction by advanced glycation end products. Arterioscler Thromb Vasc Biol 2005; 25:1401-7.

33. Guo ZJ, Niu HX, Hou FF, Zhang L, Fu N, Nagai R, et al. Advanced oxidation protein products activate vascular endothelial cells via a RAGE-mediated signaling pathway. Antiox Redox Signal 2008; 10:1699-712.

34. Hugel B, Zobari F, Freyssinet J-M. Measuring circulating cell-derived microparticles. J Thromb Haem 2004; 2:1846-7. 


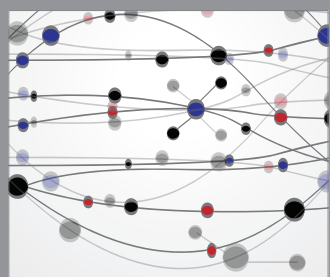

The Scientific World Journal
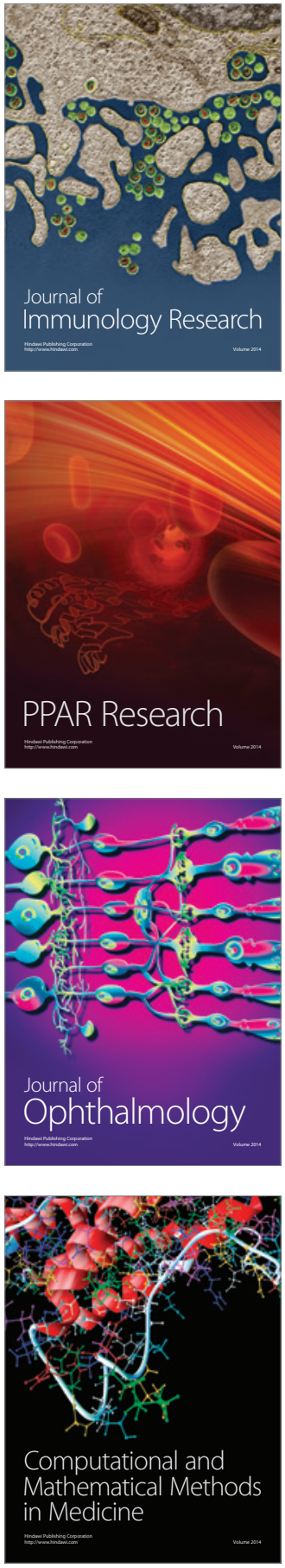

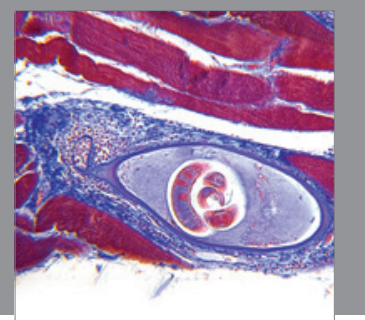

Gastroenterology

Research and Practice
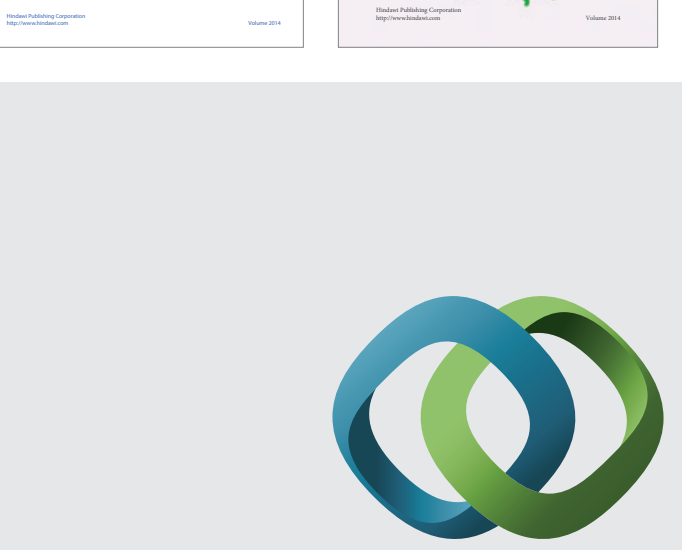

\section{Hindawi}

Submit your manuscripts at

http://www.hindawi.com
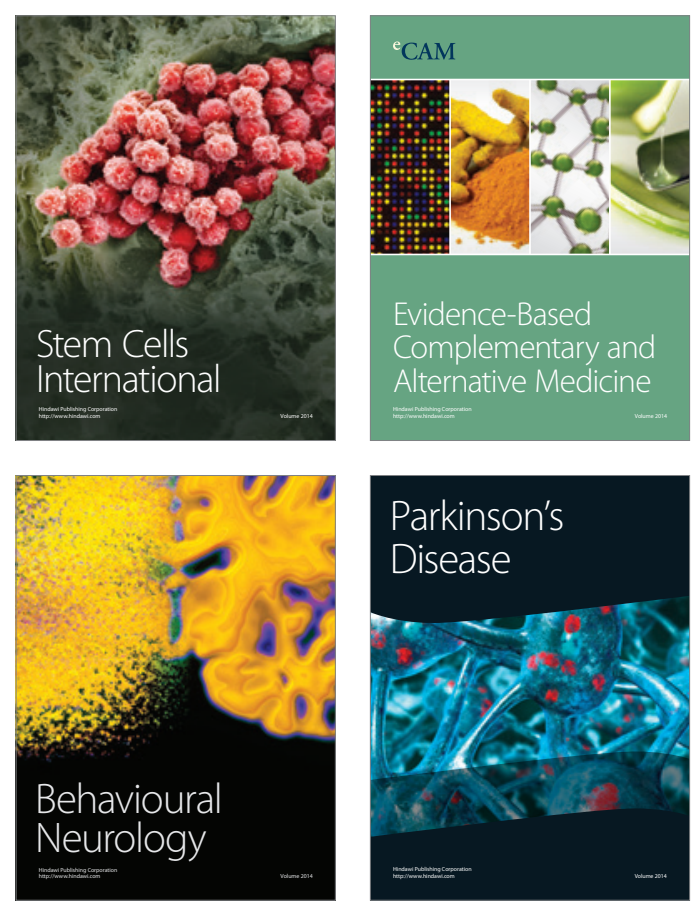

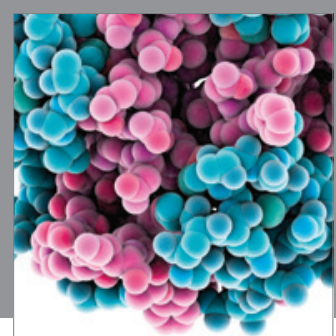

Journal of
Diabetes Research

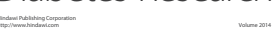

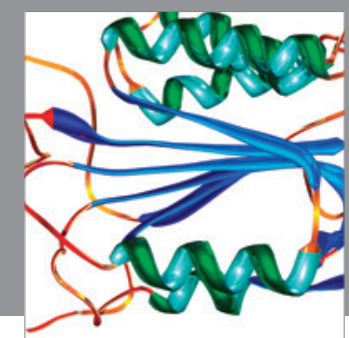

Disease Markers
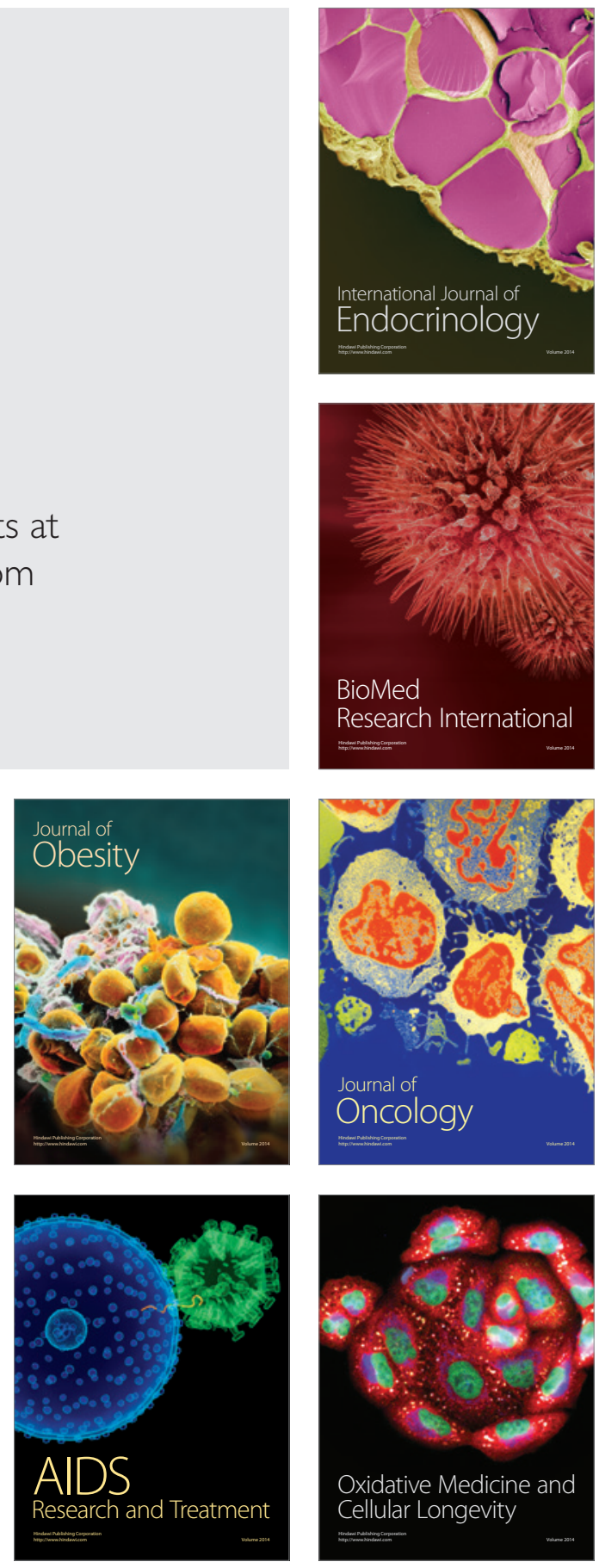